\title{
O olhar do aluno-trabalhador sobre evasão e permanência na educação técnica
}

\section{The student-worker's view of evasion and permanence in technical education \\ La mirada del alumno-trabajador sobre evasión y permanencia en la educación técnica}

\author{
RONALDO MARCOS DE LIMA ARAÚJO ${ }^{1}$ \\ RAIMUNDO BARBOSA SILVA FILHO 1 \\ ANA MARIA RAIOL DA COSTA 1 \\ ${ }^{1}$ Universidade Federal do Pará, Belém, PA, Brasil.
} \begin{abstract}
$\diamond$
RESUMO

Neste artigo objetivou-se trazer para o debate algumas causas sobre a evasão e a permanência escolar na educação sob o olhar do aluno-trabalhador que participa dos cursos técnicos subsequentes ao ensino médio do Instituto Federal de Educação, Ciência e Tecnologia do Amapá/IFAP, campus de Santana. Como metodologia, foi utilizada a pesquisa qualitativa embasada no materialismo histórico dialético e nos dados tratados com os procedimentos de análise de conteúdo. As análises das entrevistas foram divididas em três partes: perspectiva de entrada no curso; variáveis determinantes para evasão, permanência do aluno-trabalhador do IFAP/STN e expectativa e percepções pós-conclusão do curso. As variáveis mais importantes que apareceram em nossa pesquisa, causadoras da permanência e da evasão do aluno-trabalhador foram: trabalho; família; infraestrutura da escola; convivência; práticas pedagógicas e estágio. Palavras-chave: Evasão. Permanência. Aluno-trabalhador. Curso técnico.
\end{abstract}

\begin{abstract}
In this article, it was aimed at bringing to the debate causes about school dropout and permanence in education under the student-worker's view that participates in the technical courses subsequent to High School of the Federal Institute of Education, Science and Technology of Amapá/IFAP - Campus in Santana. As methodology, the qualitative research based on dialectical historical materialism and the data treated by the procedures of analysis of contents. The analyses of interview were divided into three parts, perspective of admission in the course; determinant variables for evasion; permanence of the student-worker of the IFAP/STN and post-course conclusion expectation and perception. The most cited variables that are present in our research are the cause of permanence and evasion of the studentworker, they are job; family; school infra-structure; acquaintance; pedagogical practice and internship.
\end{abstract}

Keywords: Evasion. Permanence. Student-worker. Technical course.

\section{RESUMEN}

En este artículo, se objetivó traer para el debate algunas causas sobre evasión y la permanencia escolar en la educación bajo la mirada del alumno-trabajador que participa de los cursos técnicos subsecuentes a la enseñanza media del Instituto Federal de Educación, Ciencia y Tecnología de Amapá/IFAP, Campus de Santana. Como metodología, la investigación cualitativa, basada en el materialismo histórico dialéctico y los datos tratados con los procedimientos de análisis de contenido. Los análisis de las entrevistas, dividimos en tres partes: perspectiva de entrada en el curso; variables determinantes para la evasión y permanencia del alumno-trabajador del IFAP/STN y, expectativa y percepciones posteriores a la conclusión del curso. Las variables más importantes, que aparecen en nuestra investigación las cuales son causantes de la permanencia y de la evasión del alumno-trabajador son: trabajo; familia; infraestructura de la escuela; convivencia; prácticas pedagógicas y prácticas.

Palabras clave: Evasión. Permanencia. Alumno-trabajador. Curso técnico. 


\section{INTRODUÇÃO}

As investigações que estamos propondo neste artigo, tendo como objeto o profissional subsequente ao ensino médio no estado do Amapá, campus de Santana, são de suma importância para a compreensão da dinamicidade política, social e econômica deste segmento educacional no Estado e merecem ser problematizadas e verificadas com bastante acuidade.

Com o objetivo geral de investigar possíveis causas da evasão e permanência do aluno-trabalhador do ensino técnico profissional em nível médio subsequente no IFAP/SANTANA - AMAPÁ, este estudo apresenta ainda, os seguintes objetivos específicos: identificar e analisar, na visão dos alunos, as múltiplas causas que se relacionam com a evasão de alunos-trabalhadores em cursos técnicos subsequentes do IFAP/Santana; identificar e analisar, na visão dos alunos, as múltiplas causas que se relacionam e contribuem para a permanência de alunostrabalhadores em cursos técnicos subsequentes do IFAP/ Santana.

Para a realização desta pesquisa, houve a necessidade do desenvolvimento de uma visão que compreendesse o fenômeno como um todo, investigado suas múltiplas relações, pois não existem fenômenos isolados no mundo. Por muitas vezes "confunde-se a necessária relação parte-todo e todo-parte com a ideia de um método capaz de exaurir todos os infinitos aspectos de uma determinada realidade, captar todas as contradições e todas as mediações" (FRIGOTTO, 2001, p. 81). Assim, utilizamos a linha metodológica qualitativa que "descreve o particular, explicitando, dialeticamente, suas relações com o contexto econômico, político, social e cultural" (NOSELLA E BUFFA, 2005, p.8).

Observamos nas pesquisas realizadas pelo Instituto Nacional de Estudos e Pesquisas Educacionais Anísio Teixeira - INEP (2007), Neri (2009), Programa das Nações Unidas para o Desenvolvimento - PNUD (UOL, 2013), Silva Filho e Araujo (2017) e outras, que existe alta evasão em instituições que atuam na educação profissional de nível técnico. No IFAP/STN, não é diferente.

Percebemos que a evasão escolar implica em uma visão contextualizada e ampla. Por esse motivo, trabalhamos na perspectiva do materialismo histórico- dialético, que favorece a compreensão das ocorrências sociais e naturais em movimento. Essa compreensão pode levar o pesquisador a uma visão ontológica do aluno-trabalhador e, sua historicidade poderá desvelar a realidade e criar formas de lutas eficazes no sentido da emancipação da classe trabalhadora e da superação da autorreprodução do capital. Nesse contexto, Triviños (1987, p. 51), afirma que "a realidade humana se desenvolve pela prática social da humanidade e na evolução do pensamento histórico". A prática social é considerada como critério de verdade, já que as verdades científicas não são definitivas.

Inicialmente, realizamos uma revisão bibliográfica, comum a todas as pesquisas científicas. Segundo Webster e Watson (2002), é importante que essa revisão seja bem executada e confiável, de forma sistemática e de modo compreensivo. Na sequência, utilizamos a pesquisa qualitativa pautada na interpretação do mundo real. Dentre suas abordagens, ela pressupõe um objeto interativo e surge para desvelar processos sociais na Antropologia e na Sociologia, encontrando destaque em áreas como a Administração, Educação e Psicologia. Atua também na construção e revisão de novas abordagens, conceitos e categorias referentes ao fenômeno estudado. De acordo com Minayo (2010, p.47), ela "trata do ser humano em sociedade, de suas relações e instituições, de sua história e de sua produção simbólica".

Os depoimentos dos educandos, identificados como: P1, P2, P3, P4 para os permanecentes e E1, E2, E3 e E4 para os evadidos1, corpus desta pesquisa, foram tratados com os procedimentos de análise de conteúdo - técnica empírica utilizada em tratamento de pesquisas qualitativas e quantitativas. Isso compreende a codificação e a inferência, procurando conhecer aquilo que está por trás do significado das palavras. Adotando as compreensões onde a análise do conteúdo é um conjunto de instrumentos de cunho metodológico em constante aperfeiçoamento, que se aplicam a discursos (conteúdos e continentes) extremamente diversificados (BARDIN, 2011, p. 15).

Utilizamos as seguintes estratégias metodológicas para a coleta de dados:

a) Entrevistas semiestruturadas tendo como guia um roteiro previamente elaborado com: dez questões para os alunos evadidos e dez questões para os alunos permanecentes;

b) Sujeitos da pesquisa - oito alunos-trabalhadores - consideramos o discente que estuda e trabalha - participantes dos cursos técnicos subsequentes ao ensino médio no IFAP/STN, ano 2015, em Marketing, Logística e Comércio Exterior, dentre os quais quatro são alunos evadidos e quatro são alunos permanecentes.

c) Lócus da pesquisa - O Instituto Federal de Educação, Ciência e Tecnologia do Amapá/IFAP, Campus de Santana;

d) Subsídio teórico - Utilizamos autores como Araujo (2015, 2008), Arroyo (1993), Bourdieu e Passeron (1975), Frigotto (2007, 2001), Kuenzer (2000), dentre outros pesquisadores ligados às áreas de do Trabalho e da Educação.

\footnotetext{
Optamos por utilizar códigos ao invés dos nomes dos participantes para não expor a identidade dos mesmos.
} 
Na presente pesquisa, serão utilizadas as definições de evasão para quando "o aluno sai da escola e não volta mais para o sistema escolar" (INEP, 1998); e de permanência com a ideia de que: "constituem políticas inclusivas voltadas para o acolhimento e redimensionamento de possibilidades sociais, econômicas, educacionais e culturais que atendam as singularidades desses estudantes" (DIAS A. F., 2011; DIAS, A.C.G., 2011; SOARES, 2011).

\section{EVASÃo E PERMANÊNCIA DO ALUNO-TRABALHADOR DO IFAP/SANTANA}

Analisaremos a seguir a percepção de os alunos, acerca das causas da evasão e da permanência do alunotrabalhador do ensino técnico profissional em Nível Médio Subsequente no IFAP/SANTANA. Para isso, apresentaremos a perspectiva de entrada no curso; as variáveis determinantes para evasão e permanência do aluno-trabalhador do IFAP/STN e as expectativa e percepções pós-conclusão do curso.

\section{A PERSPECTIVA DE ENTRADA NO CURSO TÉCNICO SUBSEQUENTE}

No que se refere à entrada dos estudantes dos cursos técnicos subsequentes, os dados revelam diversidades nas causas que levam o aluno-trabalhador a participar do curso técnico subsequente no IFAP/STN. Dentre essas causas, estão: a grande preocupação com o trabalho; o curso como uma possibilidade de ascensão profissional e social; de suprir as expectativas criadas pelas famílias; o curso como uma forma de desvincular-se financeiramente da família e revelar sua autonomia pessoal; a possibilidade de aprendizagem de outro idioma; estratégia de continuação da sua formação; e reforço dos estudos anteriores. Tais causas estão na origem das expectativas que motivam o aluno-trabalhador do IFAP/STN a inscrever-se nos mesmos.

Quanto a essa diversidade de causas que os levam aos cursos subsequentes no IFAP/STN, vejamos o que o aluno P1 considerou ao falar sobre sua entrada no curso, "pelo fato deles (o curso técnico subsequente) tratarem com idiomas estrangeiros (...) Quando eu vi o curso, observei que tinha inglês, espanhol, francês" $(\mathrm{P} 1 \text {, informação verbal })^{2}$. Neste depoimento, notamos a importância que ele destaca em falar um idioma a mais. Para os trabalhadores do estado do Amapá, o idioma francês, torna-se necessário em virtude de o estado ter fronteira com a Guiana Francesa. A língua é considerada

\footnotetext{
2 Depoimento de P1 em entrevista para o autor Raimundo Barbosa da Silva Filho, em 10 fev. 2017.
}

facilitadora no comércio, na cultura e até nos laços familiares entre amapaenses e guianenses ${ }^{3}$.

Outra causa que leva o estudante a cursar os cursos subsequentes, é a necessidade de continuar a estudar. Isso é revelado no depoimento do aluno P3. "Terminei o ensino médio e não queria ficar parado" ( $\mathrm{P} 3$, informação verbal) ${ }^{4}$. O jovem que conclui o ensino médio, por vezes, pensa na possibilidade de chegar o mais breve possível a uma formação profissional. O curso técnico pode ser esse caminho, uma vez que a velocidade da renovação das profissões que acontece no mercado de trabalho, aliado às incertezas sociais e econômicas, podem lhes trazer uma grande instabilidade, pois o contexto laboral presente, exige constante qualificação e técnica. Bem como Alarcão (1998) enfatiza, ao dizer que a formação continuada é um processo dinâmico por meio do qual ao longo do tempo um profissional vai adequando sua formação às exigências de suas atividades profissionais ao mercado de trabalho.

No que se refere à busca pelo o curso técnico subsequente do IFAP/STN, o aluno P4 ressalta que seu interesse por esse curso está relacionado à sua vontade de reforçar os estudos anteriores, "eu já tenho formação em Engenharia de Produção, pela UEAP (Universidade do Estado do Amapá). A escolha do curso técnico é para dar suporte a minha graduação" (P4, informação verbal $)^{5}$. Esta dinâmica multifuncional requerida ao trabalhador contemporâneo é

\begin{abstract}
Um complexo processo de construção hegemônica, [...] como uma estratégica de poder que se implementa em dois sentidos articulados: por um lado, através de um conjunto razoavelmente regular de reformas concretas no plano econômico, político, jurídico, educacional etc. e, por outro, através de uma série de estratégias culturais orientadas a impor novos diagnósticos acerca da crise e construir novos significados sociais a partir dos quais legitimar as reformas neoliberais como sendo as únicas que podem (e devem) ser aplicadas no atual contexto histórico de nossas sociedades (GENTILI, 1996, p. 9)
\end{abstract}

Esse processo hegemônico serve cada vez mais para a imposição dos ditames neoliberais, com suas regulações e seus diversos objetivos estratégicos de poderio e para a submissão das pessoas à aceitação das orientações por ele determinadas. Nesse sentido, o fazer adquirido no curso

\footnotetext{
${ }^{3}$ A respeito ver, entre outros: O impacto da Língua Francesa para a comunicação interfronteiriça: Amapá e Guiana Francesa. Disponível em: http://www2.unifap.br/cucas/files/2016/12/O-impacto-da-L\% C3\%ADngua-Francesa-para-a-comunica $\%$ C 3\%A 7\%C3\%A3ointerfronteiri\%C3\%A7a.pdf. Acesso em: 14 fev. 2019.

${ }_{4}$ Depoimento de $\mathrm{P} 3$ em entrevista para o autor Raimundo Barbosa da Silva Filho, em 8 fev. 2017.

5 Depoimento de $\mathrm{P} 4$ em entrevista para o autor Raimundo Barbosa da Silva Filho, em 5 fev. 2017.
} 
técnico como complementação do curso superior pode ser meramente um desejo mercadológico.

A realidade vem demonstrar que a junção do curso técnico com a graduação corrobora para criar novas possibilidades de atuação profissional, "Eu fiz Ciência da Computação, eu penso em aliar a tecnologia às negociações e às relações internacionais" ( $\mathrm{P} 1$, depoimento verbal $)^{6}$. Isso possibilitará ao novo técnico novas habilidades, novas possibilidades no mercado de trabalho.

Observamos que o aluno-trabalhador ao entrar no curso do IFAP/STN tem como perspectiva inicial: econômica, de realização pessoal e de dar continuidade aos estudos, essas questões serão confrontadas na seção "Expectativa e percepções pós-conclusão do curso".

\section{VARIÁVEIS DETERMINANTES PARA EVASÃO E PERMANÊNCIA DO ALUNO-TRABALHADOR DO IFAP/STN}

Neste tópico analisamos os dados da pesquisa unindo as categorias temáticas evasão e permanência. Elas nos proporcionam um olhar dialético que permitem ver a realidade em suas contradições, facilitando uma melhor compreensão da totalidade do tema estudado.

A educação é um direito social assegurado na Constituição Federal Brasileira (CF-1988), no seu artigo $6^{0}$, "São direitos sociais a educação, a saúde, o trabalho, o lazer, a segurança, a previdência social, a proteção à maternidade e à infância, a assistência aos desamparados, na forma desta Constituição", "Ter garantidas as condições de permanência, tendo em vista seu pleno desenvolvimento, seu preparo para o exercício da cidadania e sua qualificação para o trabalho" (BRASIL, 1988). Observamos, conforme apontam os dados a seguir, que o direito à educação no estado do Amapá não acontece em sua plenitude e que a evasão escolar continua preponderante no IFAP/STN.

As causas da evasão do aluno-trabalhador são difíceis de identificar, possuem uma natureza multicausal, como apontam Dore e Lüscher (2011, p. 151), ao argumentarem que cada causa subdivide-se em muitas outras e, no conjunto, compõem o quadro escolar que favorece a evasão do aluno-trabalhador, [...] influenciada por um conjunto de causas que se relacionam tanto ao estudante $\mathrm{e}$ à sua família, quanto à escola e à comunidade em que vive.

Identificar as causas percebidas pelos alunos do IFPA/ STN é socialmente necessário e relevante teoricamente, pois favorece $\mathrm{o}$ aprofundamento do reconhecimento desse fenômeno.

A seguir abordaremos as variáveis que consideramos mais importantes em nossa pesquisa, causadoras da

\footnotetext{
${ }^{6}$ Depoimento de $\mathrm{P} 1$ em entrevista para o autor Raimundo Barbosa da Silva Filho, em 10 fev. 2017.
}

permanência e da evasão do aluno-trabalhador: trabalho; família; infraestrutura da escola; convivência; práticas pedagógicas e estágio. Segundo Marchesi (2006, p. 15), estas causas encontradas no sistema educacional são oriundas, em sua maioria, das "próprias contradições que, sem dúvida, se tornam mais visíveis e, inclusive, se agravam no momento atual".

\section{Trabalho}

A necessidade de trabalhar e estudar é uma dessas contradições que obriga os alunos-trabalhadores a vivenciarem essa realidade pensando em melhorar suas vidas tanto economicamente como em conhecimento. No Brasil, diversas pesquisas apontam que a evasão escolar é influenciada pela necessidade de o jovem entrar no mercado de trabalho, seja para colaborar com o orçamento familiar, seja para seu próprio sustento (ARROYO, 1993). Isso também foi verificado em nossa pesquisa. Nas palavras dos alunos-trabalhadores, trabalhar e estudar torna-se cansativo e difícil de conciliar.

A fala do aluno E3, "estudar por si só, já é uma barra bem complicada" (E3, informação verbal) ${ }^{7}$, demonstra a grande dificuldade que os alunos trabalhadores do IFAP/STN encontram devido às condições financeiras diversas, de aprendizagem e tantas outras. "Em um país historicamente demarcado por forte desigualdade social" (DOURADO, 2005, p. 5), que circunda a vida do aluno-trabalhador, podemos ir além, e questionar, qual a sociedade que se quer construir?

Observamos que o aluno que estuda e trabalha, em grande parte, por necessitar do emprego, considera "uma barra pesada" para sua vida diária conciliar as duas coisas e acaba por desistir da escola, optando por trabalhar para sua sobrevivência. Tornando-o mão de obra precária, executando tarefas simples, pouco produtiva e de baixo valor, como sugere o capital.

Se a atividade de produção do trabalho estiver a serviço dos trabalhadores, certamente encontrará fórmulas de fixar o trabalhador na escola e no trabalho, evitando, assim, o embate entre a modernização dos processos produtivos e, atuar em favor do aluno-trabalhador e sua educação escolar. Caso contrário, podemos viver

Uma mistura inorgânica de formas escravocratas e industriais que impede a construção de uma sociedade organicamente moderna e desenvolvida... Convive-se, assim, com arroubos da modernidade, que se manifestam concomitantemente a diversas formas de expressão de um sistema produtivo desorgânico, estigmatizado pelo trabalho escravo, logo pelo nãotrabalho moderno (NOSELLA, 1993, p. 161).

\footnotetext{
Depoimento de E3 em entrevista para o autor Raimundo Barbosa da Silva Filho, em 3 fev. 2017.
} 
$\mathrm{O}$ aluno P1, por exemplo, relatou: "atualmente eu não estou trabalhando [...] trabalhar e estudar ao mesmo tempo, é um desafio muito grande tentar conciliar trabalho e estudo, porque é uma preocupação dupla, ou você preocupa-se com seu trabalho, ou com os estudos" $(\mathrm{P} 1 \text {, informação verbal })^{8}$.

Trabalhar e estudar são contradições bastantes comuns, que afetam a vivência do aluno-trabalhador nos dias de hoje, com a intencionalidade de permanecer em sala de aula e com isso manter apoio financeiro para os seus gastos pessoais e de sua família. O estudo e "[...] o trabalho parece ter invadido todos os poros da vida, ocupando parte do tempo e das preocupações do trabalhador [...]", pontua Araújo (2009, p.48). O aluno da classe trabalhadora tem a necessidade de manter-se no trabalho para subsidiar precariamente seus estudos e tentar permanecer na escola.

O aluno-trabalhador P4 aponta que, "poder conciliar (o trabalho com o estudo) logo no inicio dá, mas com o tempo vai chegando o cansaço, aquele aluno já não estuda direito" (informação verbal) 9 . Corroborando com essa ideia Siqueira (2007, p. 227) afirma que trabalhar e estudar é uma necessidade contraditória e de sobrevivência de muitos trabalhadores.

As palavras dos alunos E3, P1 e P4, representam $37.5 \%$ dos nossos entrevistados que afirmam ser o trabalho a causa com maior expressão na evasão do aluno trabalhador do IFAP/STN. Segundo Nosella e Azevedo (2009, p. 26), a ida para o trabalho é vista como uma das causas que levam à evasão e "a estrutura dualista na sociedade ainda manifesta-se 'horizontalmente', distinguindo e separando aqueles que continuam os estudos em busca da ciência, daqueles que são obrigados a deixar os bancos escolares pelas bancadas de trabalho" (2009, p. 26).

\section{Família}

A família, tem ocupado historicamente, um espaço de grande expressão no debate da evasão escolar dentro e fora do ambiente educacional. A legislação brasileira determina que a família é corresponsável juntamente com o Estado na promoção da educação. As discussões sobre evasão escolar, em parte, têm tomado como ponto central de debate o papel tanto da família, quanto da escola (DIAS, 2013, p. 9).

Os educandos citam a família como causa que interferem na evasão e na permanência do aluno da escola, conforme comentam:

\footnotetext{
${ }^{8}$ Depoimento de P1 em entrevista para o autor Raimundo Barbosa da Silva Filho, em 10 fev. 2017.

9 Depoimento de P4 em entrevista para o autor Raimundo Barbosa da Silva Filho, em 5 fev. 2017.
}

Foi um problema de família. E com isso eu me ausentava muito na semana, às vezes ia duas vezes na semana, não tinha condições de ir, o cansaço não deixava, apesar de que eu estudava à tarde, era uma hora bem complicada que a gente entrava, uma hora da tarde, na hora daquele sol quente (E1, informação verbal, grifos nossos) ${ }^{10}$.

Na minha visão as causas de evasão e desistência: Teve aluno que foi problema de família, faltava bastante, tentou voltar, mas não deu certo, parece que estava tendo problema com a justiça, a gente não entendeu muito bem, mas tentou voltar, não deu certo, não quis mais, estava comprometido demais as matérias (P1, informação verbal, grifos nossos) ${ }^{11}$.

[...], aí tem os problemas que acontece na família também. Às vezes o aluno precisa faltar durante uma semana, duas semanas, se atrapalha com os trabalhos (do curso), acumula, depois tem que repor tudo isso ( $\mathrm{P} 4$, informação verbal, grifos nossos) $)^{12}$.

Outra situação foi de alunas que tinham filhos, tinham muitos problemas em relação à saúde deles, então acabavam desistindo por causas dos bebes (P1, informação verbal, grifos nossos) $)^{13}$.

A fala dos alunos E1, P1 e P4 nos transmite a ideia de que a ausência, motivo aqui não especificado, é devida a causas familiares e, essa ausência, leva à evasão. Outra questão na fala do aluno $\mathrm{P} 1$, citada como problemas familiares, é a doença dos filhos de algumas alunas, um determinante de suas evasões da escola.

Sobre questões que associam o estudante aos familiares, Rumberger (2011) chama de causas contextuais, verificado que seu estudo empírico, é oriundo de disciplinas nas Ciências Sociais. Essas causas interferem e podem levar o educando a desistência do estudo, com isso aumentar ainda mais a desqualificação da mão de obra e consequentemente sua desvalorização e exploração pelo mercado de trabalho. Problemas familiares vivenciados pelos educandos denunciam a falta de políticas públicas educacionais capazes de devolver as possibilidades de manutenção do aluno no ambiente escolar.

\section{Infraestrutura do IFAP/STN}

Podemos perceber a ausência de democracia com as afirmações dos alunos P1, P2, P4, E1, E2, E3, ao afirmarem que a infraestrutura do IFAP/STN apresenta

\footnotetext{
${ }^{10}$ Depoimento de E1 em entrevista para o autor Raimundo Barbosa da Silva Filho, em 20 fev. 2017.

${ }^{11}$ Depoimento de P1 em entrevista para o autor Raimundo Barbosa da Silva Filho, em 10 fev. 2017.

${ }^{12}$ Depoimento de P4 em entrevista para o autor Raimundo Barbosa da Silva Filho, em 5 fev. 2017.

${ }^{13}$ Depoimento de P1 em entrevista para o autor Raimundo Barbosa da Silva Filho, em 10 fev. 2017
} 
falhas como: falta de biblioteca, laboratório sem espaço adequado, muitos computadores que não estavam funcionando, salas de aula desconfortáveis, centrais de ar que não funcionam, instalações elétricas precárias, prédio alugado, goteiras.

"A gente tinha que improvisar tudo" (P1, informação verbal) ${ }^{14}$, "na época que eu estudei (ano 2015), ainda estávamos na estrutura provisória (a nova estrutura estava em construção), estávamos em um prédio alugado, ele era pequeno, as salas não eram tão grandes, a gente ficava apertado e tudo, mas dava para gente estudar (...) tínhamos o básico necessário" (E1, informação verbal) ${ }^{15}$. Segundo Libâneo et al. (2008), espera-se que as construções, os mobiliários e o material didático sejam adequados e suficientes para assegurar o desenvolvimento do trabalho pedagógico e favorecer a aprendizagem e dessa forma evitar a evasão.

Podemos, porém, perceber que a infraestrutura por si mesma não garante a permanência do educando em sala de aula, também não garante a qualidade do aprendizado. Não são requisitos suficientes para manter o aluno na escola. Para que isso aconteça, se torna necessário a interação entre educando, infraestrutura e coerência de sua utilização (FRANCO E BONAMINO, 2005).

A má estrutura das instituições de ensino, as práticas pedagógicas defasadas, a metodologia do professor fora do contexto do educando, dificuldade para assimilar o que é ensinado etc., são problemas crônicos que levam ao "[...] encadeamento reprovação/repetência/evasão do aluno" (MARIN, 1998, p. 10). Nessa condição "é necessário intervir não só diretamente como indiretamente através da realização de um ambiente apto e conforme as necessidades que exige o desenvolvimento dos educandos." (Marx, 1986 apud LOMBARDI, 1972, p. 75).

\section{Convivência}

Um ponto destacado como causa da permanência e evasão do aluno-trabalhador, foi a convivência entre os educandos e educandos; entre educandos e professores.

É assim, era um ambiente bem agradável, eu gostava, a nossa sala, era uma sala bem ampla, éramos uma turma grande quando a gente começou, ao longo das semanas vão se evadindo, se evadindo [...] a questão do relacionamento com os mestres, eram profissionais mesmos, parecem que eles te entendiam se você estava com alguma dificuldade (E1, informação verbal, grifo nosso $)^{16}$.

\footnotetext{
14 Idem.

15 Depoimento de E1 em entrevista para o autor Raimundo Barbosa da Silva Filho, em 20 fev. 2017.

${ }^{16}$ Idem.
}

Por vezes havia também incompatibilidade com os professores, aí no IFAP/STN teve isso, o aluno saiu por não ter aquele contato com o professor, (ele disse) ah, eu não vou ficar aqui batendo cabeça. Há muitas evasões por várias causas, mas que dá para conciliar $(\mathrm{P} 2$, informação verbal $)^{17}$. A sala de aula é um espaço de múltiplas relações interpessoais, este ambiente necessita de regras claras, discutidas entre professores e alunos. São esses os sujeitos que se envolvem no cotidiano da escola e, precisam ter uma interação respeitosa entre eles. Segundo Antunes (2002, p. 26), uma boa conversa onde o professor coloca o que pretende, mas acolhe sugestões dos alunos, pode fazer com que estes descubram que regras se constroem e civismo também se treina.

\section{Prática pedagógica}

As múltiplas funções exercidas pelo docente fora da docência, tem influência direta em sua prática pedagógica, causando cansaço tanto mental quanto físico, não deixando por vezes, tempo para o planejamento de uma aula eficiente e eficaz. Isso traz grandes transtornos, podendo causar deficiência na atuação do professor. Torna-se um complicador que dificulta ainda mais o aprendizado do educando, e pode ser causadora do incentivo à evasão escolar, conforme discorre o aluno P2:

\begin{abstract}
Os professores agregavam outras funções e por isso deixavam a desejar [...] as aulas eram boas, eram satisfatórias, nem todas, mas eram. Os professores, todos eles, sem exceção, eles eram bem esforçados, eles queriam o nosso melhor, eles nos apoiavam em muitas coisas. [...] o professor não era somente professor da disciplina: ele tinha que está no IFAP de Macapá; buscando parcerias; tinha outras funções, ele deixava um pouco a desejar, mas ele é muito competente ( $\mathrm{P} 2$, informação verbal, grifo nosso $)^{18}$.
\end{abstract}

As atividades exercidas pelos docentes, as quais não fazem parte da sua função, possivelmente devem ser uma exigência da instituição educacional onde o professor atua. Esquece a instituição que a função docente precisa de tempo para "uma prática fertilizada pela reflexão teórica, portanto, carregada de sentido, de significado, e uma teoria fertilizada, provocada, desafiada pelas questões da prática" (VASCONCELLOS, 1998, p. 87).

A forma como o professor executa sua metodologia tem influência direta no aprendizado do aluno: "Você olha para o professor, você sabe que o professor tem domínio, tem total domínio, ele sabe, o cara é fera,

\footnotetext{
${ }_{17}$ Depoimento de P2 em entrevista para o autor Raimundo Barbosa da Silva Filho, em 15 fev. 2017.

${ }^{18}$ Idem.
} 
mas na hora de passar o conteúdo ele não sabia muito (P2, informação verbal, grifo nosso) ${ }^{19}$; "Eu vi que eles (os professores) estavam muito presos à sala de aula, era muito slide, era uma aula muito cansativa, muito teórica" (P1, informação verbal, grifo nosso ${ }^{20}$; As aulas eram maravilhosas, não tenho o que reclamar do IFAP/STN em relação a professor e a conhecimento, não tenho nada para reclamar mesmo (E2, informação verbal, grifo nosso $)^{21}$.

O saber do docente em um sentido amplo, contextualiza o conhecimento, as competências, as habilidades e as atitudes, é o saber-fazer e saber-ser. Para Tardif (2000, p. 11),

[...] os saberes profissionais são saberes trabalhados, lapidados e incorporados no processo de trabalho docente e que só têm sentido em relação às situações de trabalho concretas, em seus contextos singulares e que é nessas situações que são construídos modelados e utilizados de maneira significativa pelos trabalhadores do ensino.

Segundo Gauthier (1998) o saber necessário para ensinar não deve ser visto apenas como conhecimento do conteúdo da disciplina. $\mathrm{O}$ professor necessita muito mais do que conhecer a matéria, mesmo sabendo que esse conhecimento é fundamental. Pensou-se por muito tempo que as habilidades necessárias à docência podiam ser resumidas ao talento, à intuição, à experiência e à cultura do professor. Essas ideias prejudicavam o processo de profissionalização do ensino, impedindo o surgimento de um saber desse ofício sobre si mesmo. É o que se denomina de um ofício sem saberes.

Araujo cita algumas características necessárias ao docente na atuação da educação profissional:

intelectual, problematizador, mediador do processo ensino-aprendizagem, promotor do exercício da liderança intelectual, orientador sobre o compromisso social que a ideia de cidadania plena contém, orientador sobre o compromisso técnico dentro de sua área de conhecimento (ARAUJO, 2008, p.9)

\section{Estágio supervisionado}

Esta variável, dentre as que trouxemos para a discussão de nossa pesquisa empírica, é a única que não aparece em nossa revisão bibliográfica, o que dá um diferencial ao IFAP/STN. O estágio supervisionado não é tratado como prioridade, foi um problema apontado repetidas vezes

\footnotetext{
${ }^{19}$ Idem.

${ }^{20}$ Depoimento de $\mathrm{P} 1$ em entrevista para o autor Raimundo Barbosa da Silva Filho, em 10 fev. 2017.

${ }^{21}$ Depoimento de E2 em entrevista para o autor Raimundo Barbosa da Silva Filho, em 20 fev. 2017.
}

pelos educandos, a promessa de estágio supervisionado. O mesmo não aconteceu da forma como foi apresentado aos educandos no início do curso e, substituído por trabalho científico, causou muitas insatisfações:

Essa parte do estágio foi bem polêmica, porque eles (o IFAP/STN) não tiveram essas vagas para todos os alunos, surgiram uma ou duas vagas nas empresas de transporte. A gente via mais a parte logística (...) a gente ficou mesmo com trabalho científico para suprir essas horas do estágio (P1, informação verbal, grifo nosso $)^{22}$.

É na fase do estágio, fonte de aprendizagem, que o aluno-trabalhador coloca em prática o conhecimento absorvido durante o período das fundamentações teóricas e começa a fazer a relação com o seu cotidiano laboral, afirma Santos (2010, p.5), “[...] teoria e prática mantêm uma relação de unidade na diversidade, formam uma relação intrínseca, sendo o âmbito da primeira o da possibilidade e o da segunda o da efetividade". É o momento do contato da realidade profissional e do olhar crítico sobre o mundo do trabalho, através da observação e posterior intervenção na atividade proposta pelo curso. É a oportunidade de aproximação da realidade profissional, instrumento da práxis e, portanto, passa a integrar o corpo de conhecimentos do curso em formação (PIMENTA; LIMA, 2004, p. 55).

As diferenças existentes entre o contexto do aluno e o contexto da escola é uma causa determinante para a evasão, a escola precisa ser capaz de prevenir situações que levam à exclusão ou à segregação dos alunos, "estudos propõe como o encaminhamento mais adequado para o problema é a 'prevenção' - identificação precoce do problema e acompanhamento individual daqueles que estão em situação de risco" (EUROPEAN COUNCIL, 2004, p. 105).

\section{EXPECTATIVA E PERCEPÇÕES PÓS-CONCLUSÃO DO CURSO}

As expectativas e as percepções do educando do IFAP/STN pós-conclusão do curso técnico subsequente, poderão servir como caminho para uma análise mais profunda e mais elaborada da trajetória durante a execução dos referidos cursos, tanto pela Instituição, quanto pelo corpo técnico, docentes e discentes.

Essa expectativa do educando deve corresponder aos seus objetivos pessoais e profissionais e, relacionar-se com as habilidades adquiridas no curso para serem executadas no momento do exercício profissional e vivencial. Ele

\footnotetext{
${ }^{22}$ Depoimento de P1 em entrevista para o autor Raimundo Barbosa da Silva Filho, em 10 fev. 2017.
} 
deve verificar se as habilidades adquiridas correspondem ao que foi prometido inicialmente pela instituição e se essas habilidades podem ser aplicadas no dia a dia da sua profissão. $\mathrm{O}$ aluno $\mathrm{P} 3$ discorre sobre as dificuldades encontradas durante o curso e questiona a dificuldade de encontrar trabalho:

Quanto ao mercado de trabalho, eu não vejo, eu não vejo. Tem empresas grandes que a gente conhece que importam e exportam mercadorias. Mas nem estágio nós tivemos, então sei lá, parece que não existe oportunidade para a área de comercio exterior, talvez se reformassem o porto ${ }^{23}$ (da Cidade de Santana) as coisas melhorassem $(\mathrm{P} 3$, informação verbal, grifo nosso $)^{24}$.

O olhar do aluno E1, contradiz o educando anterior, mesmo sendo evadido, considera que o mercado está aberto aos técnicos:

Eu vi o curso como uma porta de entrada para o progresso, principalmente aqui no município de Santana, a prova é que hoje já estamos exportando os grãos. Alguns colegas meus que se formaram, já estão trabalhando, foram profissionalizados pelo Instituto $(\mathrm{E} 1 \text {, informação verbal, grifo nosso })^{25}$.

Com o mercado de trabalho cada vez mais concorrido, faz-se necessário ao técnico que inicia ou já está atuando como profissional demonstrar seu saber, seu engajamento e determinação como resultado ativo do processo educacional por ele vivido, uma visão crítica e participativa em sua área de atuação poderá ser facilitadora da sua entrada e sua permanência no mercado de trabalho, somente a formação profissional e tecnológica não é suficiente.

O próprio capital moderno reconhece que os trabalhadores necessitam ter acesso à cultura sob todas as formas e, portanto, à educação básica. Desta maneira, a escola tende progressivamente a se transformar, propiciando a aquisição de: princípios científicos gerais que impactam sobre o processo produtivo; habilidades instrumentais básicas que incluem formas diferenciadas de linguagens próprias, envolvendo diversas atividades sociais e produtivas;

\footnotetext{
${ }^{23}$ Em março de 2013, um píer flutuante do porto desabou em razão de uma movimentação de terra, tragando parte do porto e de seus equipamentos para dentro do Rio Amazonas, além de fazer seis vítimas fatais. Os prejuízos com a perda de máquinas e de receitas por conta da paralisação da operação são estimados em torno de R\$ 670 milhões. Disponível em: https://www.brasil247.com/pt/247/amapa247/144196/Trag\%C3\%A9diaem-Santana-Empresas-disputam-indeniza $\% \mathrm{C} 3 \% \mathrm{~A} 7 \% \mathrm{C} 3 \% \mathrm{~A} 3 \mathrm{o} . \mathrm{htm}$. Acesso em 5 abr. 2017.

${ }^{24}$ Depoimento de P3 em entrevista para o autor Raimundo Barbosa da Silva Filho, em 08 fev. 2017.

${ }^{25}$ Depoimento de E1 em entrevista para o autor Raimundo Barbosa da Silva Filho, em 20.fev. 2017.
}

categorias de análise que facilitam a compreensão histórico-crítica da sociedade, das formas de atuação do ser humano, como cidadão e trabalhador; capacidade instrumental de exercitar o pensar, o estudar, o criar e o dirigir, estabelecendo os devidos controles (BRASIL, 2004, p. 8)

As perspectivas dos alunos-trabalhadores pósconclusão do curso, se aproximam das perspectivas de entrada no curso:

a) Quanto da perspectiva econômica - "Quanto ao mercado de trabalho, eu não vejo, eu não vejo" (P3, informação verbal $)^{26}$. "Eu vi o curso como uma porta de entrada para o progresso, principalmente aqui no município de Santana, a prova é que hoje já estamos exportando os grãos. Alguns colegas meus que se formaram já estão trabalhando, foram profissionalizados pelo Instituto (IFAP/STN)" (E1, informação verbal) ${ }^{27}$;

b) Realização pessoal - Ele (o curso) me trouxe incentivo, ele me trouxe até uma mudança de visão da profissão, (...) foi algo que me surpreendeu em temos de cursos (E1, informação verbal) ${ }^{28}$;

c) Continuidade dos estudos - não houve qualquer referência sobre essa perspectiva.

De imediato, fazem-se necessárias políticas que reduzam a reprovação no ensino fundamental e médio e que, consequentemente, melhorem o fluxo escolar. A evasão compromete o processo de democratização do ensino técnico. Entender suas causas poderá ser a chave para encontrar soluções para a permanência do alunotrabalhador na escola. O contexto teórico da investigação segundo Dore e Lüscher (2011, p. 777b),

Mostra a exigência de associar o estudo da evasão escolar ao estudo das causas sociais, institucionais e individuais que podem interferir na decisão de estudantes, sobre permanecer na escola ou evadir-se, antes da conclusão de um curso. Assim, é necessário considerar desde o tipo de inserção do estudante no contexto social mais amplo, o que envolve questões econômicas, sociais, políticas, culturais e educativas, até suas próprias escolhas, desejos e possibilidades individuais.

A evasão é um problema que traz consequências que ultrapassam o aluno evadido e chega à sociedade como um todo e, é dever de toda sociedade combatê-la. Porém, sem a compreensão de suas causas, fica difícil entender a realidade destes educandos (RUMBERGER, 1995, p. 585).

\footnotetext{
${ }^{26}$ Depoimento de P3 em entrevista para o autor Raimundo Barbosa da Silva Filho, em 8 fev. 2017

27 Depoimento de E1 em entrevista para o autor Raimundo Barbosa da Silva Filho, em 20 fev. 2017.

${ }^{28}$ Idem.
} 
Sabemos da importância da carreira técnica para grande parte da população brasileira e, a escola pública, como participante deste corolário, onde questões sociais, econômicas, culturais, etc., estão envolvidas, pode ser a promotora do início, da permanência e da continuidade da carreira dos jovens. Pode fazer uma educação transformadora que desenvolva práticas pedagógicas de acordo com o contexto em que o aluno está inserido. Sua proposta política pedagógica deve ser

(...) o diferencial, centrada no debate e na concepção da escola unitária e politécnica; uma escola comprometida em formar jovens que articulem ciência, cultura e trabalho e lhes dê a possibilidade de serem cidadãos autônomos; que possam escolher seguir seus estudos ou, se têm necessidade, ingressar na vida profissional (FRIGOTTO, 2007, p. 1146).

A educação profissional técnica subsequente precisa ter sua identidade comprometida com a educação do aluno-trabalhador. O emprego do saber necessita ter a compreensão do contexto dos sujeitos envolvidos, indo além das práticas conteudistas, enciclopédicas e fisiologistas que envolvem o ambiente educacional.

Consideramos que a educação profissional técnica subsequente ao ensino médio no Brasil precisa estar comprometida com uma "formação inteira", que não se satisfaz com a socialização de fragmentos da cultura sistematizada e que compreende como direito de todos ao acesso a um processo formativo, inclusive escolar, que promova o desenvolvimento de suas amplas faculdades físicas e intelectuais (ARAUJO, 2015, p. 63-64).

\section{CONSIDERAÇõES FINAIS}

A evasão e a permanência escolar são temas complexos, difíceis de serem verificados em função do grande número de causas envolvidas, como: drogas, reprovações na escola, problemas familiares, defasagem no ensino, necessidade de entrar com maior brevidade no mercado de trabalho, saída para a educação superior, infraestrutura física da escola, metodologia do professor, etc. Todas influenciam diretamente na definição de evasão e permanência do educando no ambiente escolar.

$\mathrm{Na}$ presente pesquisa encontramos as causas que definem a evasão ou a permanência do aluno-trabalhador no IFAP/STN e percebemos como esse fenômeno acontece no ambiente escolar, nos possibilitando um olhar mais agudo e mais completo, conforme o seguinte:

a) A perspectiva de entrada no curso técnico subsequente:

- A importância que o aluno destaca em falar um idioma a mais, principalmente o francês;
- O fato da necessidade de continuar a estudar;

- Interesse está relacionado a sua vontade de reforçar seus estudos anteriores;

- A junção do conhecimento do curso técnico com o conhecimento da graduação corrobora para criar novas possibilidades de atuação profissional.

b) Causas determinantes para a evasão e permanência escolar no IFAP/STN:

- Trabalhar e estudar torna-se cansativo e difícil de conciliar;

- Dificuldade de manter-se na escola e no trabalho traz como consequência a evasão, com isso, a baixa qualificação profissional;

- Problemas pessoais aparecem como causas que interferem na saída do aluno da escola;

- Infraestrutura deficitária da escola;

- Boa convivência entre os educandos e educandos, entre educandos e professores, entre educandos e corpo técnico;

- Incompatibilidade com os professores;

- As múltiplas funções exercidas pelos professores fora da docência, por esse motivo, deixavam a desejar sua prática profissional;

- A forma como o professor executa sua metodologia tem influência direta no aprendizado do aluno;

- Falta de estágios.

c) Expectativa e percepções pós-conclusão do curso:

- Dificuldade de encontrar trabalho;

- Considera que o mercado está aberto aos técnicos.

Podemos inferir que as causas que agem na permanência, quanto na evasão escolar, são bastante complexas e de difícil compreensão, suas interpretações polissémicas e multifacetadas, dificultam ainda mais as análises no momento do seu estudo. Essas causas agem em várias frentes, podendo se apresentar na vida do aluno-trabalhador ao mesmo tempo, deixando-o em situação tão difícil, que sem apoio de uma política pública educacional efetiva, o mesmo pode ser conduzido para fora do ambiente escolar.

As expectativas de entrada, as causas da evasão e perspectivas pós-conclusão do curso técnico subsequente ao ensino médio analisado na pesquisa de campo deste estudo, nos mostram que há um longo caminho a percorrer, que as mesmas podem ser provisórias, deixando espaço para novas conclusões e novas investigações.

\section{REFERÊNCIAS}

ALARCÃO, Nilda. Trajetórias e Redes na Formação de Professores. Rio de janeiro: DP\&A. 1998. 
ANTUNES, Celso. Novas maneiras de ensinar. Novas formas de aprender. Porto Alegre: Artmed, 2002.

ARAUJO, Ronaldo Lima Araujo; FRIGOTTO, Gaudêncio. Práticas pedagógicas e Ensino integrado. Revista Educação em Questão, Natal, v. 52, n. 38, p.61-80, maio/ago. 2015.

ARAUJO, Ronaldo Marcos de Lima. Formação de docentes para a educação profissional e tecnológica: por uma pedagogia integradora da educação profissional. Trabalho e Educação, Campinas, v. 17, n. 2, p. 53-63, maio/ago. 2008.

ARAÚJO, Silvia Maria de. Sociologia: um olhar crítico. São Paulo: Contexto, 2009.

ARROYO, Miguel G. Educação e exclusão da cidadania. In: BUFFA, Ester (org.). Educação e cidadania: quem educa o cidadão. 4. ed. São Paulo: Cortez, 1993.

BARDIN, Laurence. Análise de conteúdo. São Paulo: 70, 2011. 229 p.

BOURDIEU, P; PASSERON, J. C. A reprodução: elementos para uma teoria do sistema de ensino. Rio de Janeiro: Francisco Alves, 1975.

BRASIL tem 3a maior taxa de evasão escolar entre 100 países, diz Pnud. UOL Educação, São Paulo, 14 de mar. 2013. Disponível em: https://educacao.uol.com.br/ noticias/2013/03/14/brasil-tem-3-maior-taxa-de-evasaoescolar-entre-100-paises-diz-pnud.htm?cmpid. Acesso em: 14 maio 2016.

BRASIL. Instituto Nacional de Estudos e Pesquisas Educacionais Anísio Teixeira - INEP. Censo Escolar de 2008. Brasília, 2007.

BRASIL. Ministério da Educação. Secretaria da Educação Profissional e Tecnológica. Políticas Públicas para a Educação Profissional e Tecnológica: proposta em discussão. Brasília, 2004.

BRASIL. Constituição (1988). Constituição da República Federativa do Brasil. Brasília, DF: Senado Federal, 1988.

DIAS, Mirian Viviane. Evasão Escolar no Ensino Fundamental. 2013. Monografia (Graduação em Biologia) - Faculdade de Biologia, IFSUL de Minas Gerais, Machado, 2013. Disponível em: http://www.mch.ifsuldeminas.edu. br/ biblioteca/biblioteca digital/Documentos/TCCdaiologia2013/TCC-Mirian.PDF. Acesso em: 17 nov. 2017.

DIAS, Aline Fávaro. O jovem autor de ato infracional e a educação escolar: significados, desafios e caminhos para a permanência na escola. 2011. 169 p. Dissertação (Mestrado em Educação) - Programa de Pós-Graduação em Educação, Universidade Federal de São Carlos, São Carlos, 2011.

DIAS, Ana Cristina Garcia; ARPINI, Dorian Mônica; SIMON, Bibiana Rosa. Um olhar sobre a família de jovens que cumprem medidas socioeducativas. Psicologia e Sociedade, Florianópolis, v. 23, n. 3, p. 526-535, set./dez. 2011. https://doi.org/10.1590/S0102-71822011000300010
DORE, Rosemary; LÜCSCHER, Ana Zuleima. Permanência e evasão a educação técnica de nível médio em Minas Gerais. Cadernos de Pesquisas, v.41, n. 144, p. 770-789, dez. 2011a. https://doi.org/10.1590/S0100-15742011000300007

DORE, Rosemary; LÜCSCHER, Ana Zuleima. Permanência e evasão na educação técnica de Nível Médio em Minas. Cadernos de Pesquisa, v. 41, n. 144, p. 772, set./dez. 2011b.

DOURADO, Luiz Fernandes. Elaboração de políticas estratégicas para a preservação do fracasso escolar Documento Regional BRASIL: Fracasso escolar no Brasil: Políticas, programas e estratégias de prevenção ao fracasso escolar. Brasília, 2005. Disponível em: https://www.oei. es/historico/quipu/brasil/sistema_nacional_formacion profesores.pdf. Acesso em: 25 mar. 2019.

EUROPEAN COUNCIL. Achieving the Lisbon goal: the contribution of VET: Final report to and Schools. American Educational Research Journal, v. 32, n. 3, p. 583-625, 1995. The European Commission 1 nov. 2004. Disponível em: http://ec.europa.eu/education/policies/2010/studies/ maastrichten.pdf. Acesso em: 27 jul. 2017.

FRANCO, C.; BONAMINO, A. A pesquisa sobre característica de escolas eficazes no Brasil: breve revisão dos principais achados e alguns problemas em aberto. Educação online PUC-Rio, Rio de Janeiro, n. 1, p. 2-13, 2005.

FRIGOTTO, Gaudêncio. A relação da educação profissional e tecnológica com a universalização da educação básica. Edu. Soc., Campinas, v. 28, n. 100, p. 1129-1152, out. 2007. Edição especial. Disponível em: http://www.cedes.unicamp.br. Acesso em: 11 ago. 2017.

FRIGOTTO, Gaudêncio. O enfoque da dialética materialista histórica na pesquisa educacional. In: FAZENDA, I. (org.). Metodologia da pesquisa educacional. 7. ed. São Paulo: Cortez, 2001. p. 69-90.

GAUTHIER, Clemont. Por uma teoria da Pedagogia. Ijuí: UNIJUÍ, 1998.

GENTILI, Pablo. Neoliberalismo e Educação: Manual do Usuário. In: SILVA, Tomaz T. (org.). Escola S.A. Brasília: CNTE, 1996.

KUENZER, A. Z. O ensino médio agora é para a vida: entre o pretendido, o dito e o feito. Educação e Sociedade, Campinas, v. 1, p. 15-39, 2000. https://doi.org/10.1590/S010173302000000100003

LIBÂNEO, J.; FERREIRA, J.; SEABRA, M. Educação escolar: políticas, estrutura e organização. 6. ed. São Paulo: Cortez, 2008.

LOMBARDI, F. Las ideas pedagógicas de Gramsci. Barcelona: Redendo, 1972.

MARCHESI, A. O que será de nós, os maus alunos? Porto Alegre: Artmed, 2006. 
MARIN, A. J. Com o olhar nos professores: desafios para o enfrentamento das realidades escolares. Cadernos CEDES, Campinas, v. 19, n. 44, p. 8-18, abr. 1998. https://doi. org/10.1590/S0101-32621998000100002

MINAYO, M. C. de S. O desafio do conhecimento: Pesquisa Qualitativa em Saúde. 12. ed. São Paulo: Hucitec-Abrasco, 2010 .

NERI, Marcelo Cortês. Tempo de permanência na escola e as motivações dos sem-escola. Rio de Janeiro: FGV: IBRE: CPS, 2009.

NOSELLA, Paolo; AZEVEDO, Mário Luiz Neves de. A educação em Gramsci. In: FALCO, Aparecida Meire Calegari (org.). Sociologia da Educação: múltiplos olhares. 2. ed. Maringá: EDUEM, 2009.

NOSELLA, Paolo; BUFFA, Ester. As pesquisas sobre instituições escolares: o método dialético marxista de investigação. São Paulo: UNICAMP, 2005.

NOSELLA, Paolo. A Modernização da Produção e a Escola no Brasil: o estigma da relação escravocrata. Porto Alegre: ANPED, 1993.

PIMENTA, Selma Garrido; LIMA, Maria Socorro Lucena. Estágio e Docência. São Paulo: Cortez, 2004.

RUMBERGER, R. W. Introduction. In: DROPPING out: why students drop out of high school and what can be done about it. Cambridge, Mass: Harvard University Press, 2011. p. 1-19. https://doi.org/10.4159/harvard.9780674063167

RUMBERGER, R. W. Dropping out of middle school: a multilevel analysis of students and schools. American Educational Research Journal, v. 32, n. 4, p. 583-625, 1995. https://doi.org/10.3102/00028312032003583

SANTOS, C. M. dos. Na prática a teoria é outra? Mitos e dilemas na relação entre teoria, prática, instrumentos e técnicas no Serviço Social. Rio de Janeiro: Lumen Juris, 2010.

SILVA FILHO, Raimundo Barbosa da; ARAUJO, Ronaldo Marcos de Lima. Evasão e abandono escolar na educação básica no Brasil: fatores, causas e possíveis consequências. Educação Por Escrito, Porto Alegre, v. 8, n. 1, p. 35-48, jan./jun. 2017. https://doi.org/10.15448/2179-8435.2017. 1.24527

SIQUEIRA, Janes Fraga. A realidade contraditória e de sobrevivência do jovem trabalhador e estudante nas escolas estaduais de Porto Alegre/RS/Brasil. Rexe, v. 1, n. 1, p. 227-244, 2007. Disponível em: https://dialnet.unirioja.es/ ejemplar/178799. Acesso em: 15 nov. 2017.

SOARES, Ana Cristina Silva. A inclusão de alunos com deficiência visual na Universidade Federal do Ceará: ingresso e permanência na ótica dos alunos, docentes e administradores. 2011, 240 p. Tese (Doutorado em Educação) - Programa de Pós-Graduação em Educação Brasileira. Universidade Federal do Ceará, 2011.
TARDIF, Maurice. As concepções do saber dos professores de acordo com diferentes tradições teóricas e intelectuais. Rio de Janeiro: PUC-Rio, 2000. Mimeografado.

TRIVIÑOS, Augusto Nibaldo Silva. Introdução à pesquisa em ciências sociais: a pesquisa qualitativa em educação. São Paulo: Atlas, 1987.

VASCONCELLOS, C. dos S. Para Onde Vai o Professor? Resgate do professor como sujeito de transformação. São Paulo: Libertad, 1998.

WEBSTER, J.; WATSON, J. T. Analyzing the past to prepare for the future: writing a literature review. MIS Quarterly. 2002.

Recebido em: 30/11/2017

Aprovado em: 27/12/2018.

Publicado em: 30/4/2019.

Endereço para correspondência:

Ronaldo Marcos de Lima Araújo

Universidade Federal do Pará

Instituto de Ciências da Educação (ICED)

Departamento de Fundamentos da Educação (DFE)

Rua Augusto Corrêa, 01 - Guamá

66075-110, Belém, PA, Brasil

Autores:

RonAldo MARCos DE LIMA ARAÚJO

Doutor em Educação. Universidade Federal do Pará (UFPA), Belém, PA, Brasil. Orcid: http://orcid.org/0000-0002-5982-793X

E-mail: rlima@ufpa.br

RAIMUNDO BARBOSA SILVA FILHO

Mestre em Educação. Universidade Federal do Pará (UFPA), Belém, PA, Brasil. Orcid: http://orcid.org/0000-0003-3001-7287

E-mail: prof.barbosa001@hotmail.com

ANA Maria RaIOL DA Costa

Mestra em Educação. Universidade Federal do Pará (UFPA), Belém, PA, Brasil. Orcid: https://orcid.org/0000-0003-2588-9507

E-mail: anaraioldavi@gmail.com 